\title{
Review on Power System Frequency Regulation with High Wind Power Permeability
}

\author{
Zijian Ye1, Yuyan Xie'2, Haochuan Zhu' \\ ${ }^{1}$ Nari School of Electrical Engineering, Nanjing Normal University, Nanjing, China \\ ${ }^{2}$ School of Chemistry and Materials Science, Nanjing Normal University, Nanjing, China \\ Email: 1528990874@qq.com
}

How to cite this paper: Ye, Z.J., Xie, Y.Y. and Zhu, H.C. (2018) Review on Power System Frequency Regulation with High Wind Power Permeability. Energy and Power Engineering, 10, 366-382. https://doi.org/10.4236/epe.2018.108023

Received: July 18, 2018

Accepted: August 24, 2018

Published: August 27, 2018

Copyright ( 92018 by authors and Scientific Research Publishing Inc. This work is licensed under the Creative Commons Attribution International License (CC BY 4.0).

http://creativecommons.org/licenses/by/4.0/

(c) (i) Open Access

\begin{abstract}
In recent years, global wind power has developed rapidly to alleviate environmental pollution and energy crisis. Due to the potential of enhancing the stability of power system through the application of wind power participating in power grid frequency regulation, the large-scale integration of wind power has become a hot issue for academic research in recent years. This paper classifies the frequency control problems of wind power integration and summarizes the research of power system frequency regulation strategy with high wind power permeability. Energy storage system participating in frequency regulation of the power system with high wind permeability is reviewed and analyzed.
\end{abstract}

\section{Keywords}

Wind Power, Frequency Regulation, Control Strategy

\section{Introduction}

With the rapid development of the economy, the global demand for electricity also grows rapidly. Taking China as an example, by the end of 2017, the total installed power generation capacity of China has been up to 1.78 billion $\mathrm{kw}$ [1]. With the gradual depletion of fossil fuels and increasing environmental pollution, the researchers are gradually developing new energy sources such as photovoltaic and wind power. Among them, wind power is particularly valued because of its clean pollution and wide distribution of resources. And its power generation cost has been greatly reduced in recent years [2]. In the other hand, the total installed capacity of wind power in the world has reached a very high level. The market for wind power in 2017 was led by China, Germany and India. Countries such as France, Turkey and Netherlands have performed more than 
expected. China tops the list with 168,690 megawatts of installed wind power, accounting for 34.7 percent of global installed capacity. The United States and Germany account for the second and third place respectively with $82,183 \mathrm{Mw}$ and $50,108 \mathrm{Mw}$, accounting for $16.9 \%$ and $10.3 \%$ of the total installed capacity of wind power in the world [3].

With the increase of wind power capacity, wind power permeability in power gird has been improved. However, the intermittent, uncontrollable and uncontrollable wind energy has caused the randomness of wind power generation. This will also bring serious challenges to the security, reliability and economy of the power system. Power generation plan and frequency regulation control strategy based on traditional load forecasting have great pressure in maintaining the frequency deviation of the system [4]. Therefore, the frequency control of system will become the limiting factor for the further improvement of wind power permeability.

At present, the frequency control problem of wind power grid can be divided into the following two kinds of countermeasures: 1 ) Wind turbines participate in system frequency regulation. The concrete implementation methods mainly include the wind turbines' own active power control and the additional energy storage system control. Wind turbines provide frequency regulation for the power system. 2) To improve the frequency regulation capability of generators units. Automatic generation control (AGC) units and smart grid should be proposed. Such countermeasures are generally focused on dynamically balancing power fluctuations by improving the secondary frequency regulation capability of the power system with high wind power. But it is also a hot research that improves the control ability of low frequency disturbance by regulating the dynamic primary frequency. Based on the above two kinds of countermeasures, this paper summarizes the control strategy of power system frequency regulation with high wind power. The principles, advantages and disadvantages of various control strategies are also clarified. Finally, this paper introduces the study on energy storage system participating in frequency regulation of the power system with high wind permeability.

\section{Wind Turbines Participate in System Frequency Regulation}

Wind turbines can be divided into two categories, constant speed wind turbines and variable speed wind turbines. Fixed speed wind turbines are similar to the traditional thermal power units, whose rotor speed can be directly coupled with the power system frequency, and can respond to the frequency fluctuation of the power system. However, the fixed speed wind turbine is mainly used for small capacity wind power generation. As the fan capacity increases gradually, the variable speed wind turbine unit becomes the current mainstream wind power unit. The variable speed wind turbine is composed of double-fed induction generators (DFIGs) and direct drive wind turbines, both of which are connected by 
the power electronic converters with power gird, and causes the fan rotor speed to be decoupled from the system frequency. This results in the failure of the variable speed fan to provide the inertial response and primary frequency regulation. And the frequency fluctuation of power system cannot be actively responded [5]. Therefore, in order to realize the participation of variable speed wind turbine in frequency modulation, the auxiliary control of wind turbine must be carried out. Generally, it is realized through the active power control of the wind turbine itself, which can be divided into power reserve control [6]-[15] and kinetic energy control [16]-[23]. Power reserve control mainly includes pitch control and rotor speed control; Kinetic Energy Control includes inertial control, droop control and integrated inertial control.

\subsection{Power Reserve Control}

Reserve power control is also called reduction control, its principle is that the output force of the fan is less than the maximum by means of pitch control and rotor speed control, so as to reserve a certain power reserve and support the system frequency regulation. Wind turbines work at the sub-optimal power tracking point [6]. In order to avoid excessive loss of life and considering the rotor speed control by the rated wind speed limit, when the wind speed is higher than the rated wind speed, wind turbines use pitch control method; when the wind speed is lower than the rated wind speed, wind turbines use rotor speed control method [7]. Because these two methods adopt independent control system, the study can be carried out separately. Figure 1 shows the schematic diagram of wind turbines lightening running under pitch control and variable speed control [8].

\subsubsection{Pitch Control}

The control model of pitch control is shown in Figure 2, where $P_{\mathrm{w}}$ is the actual

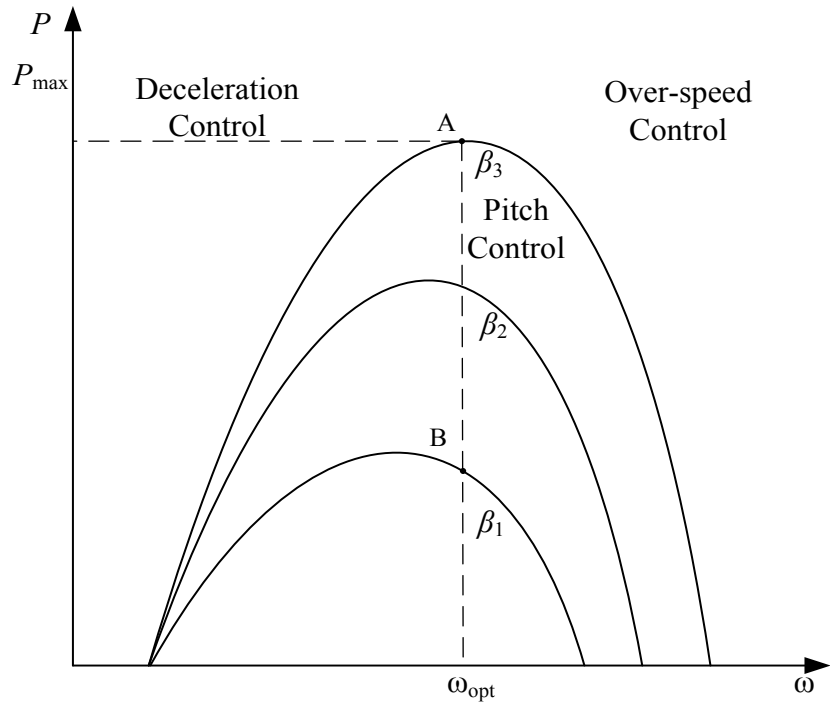

Figure 1. Lightening running under two control methods. 


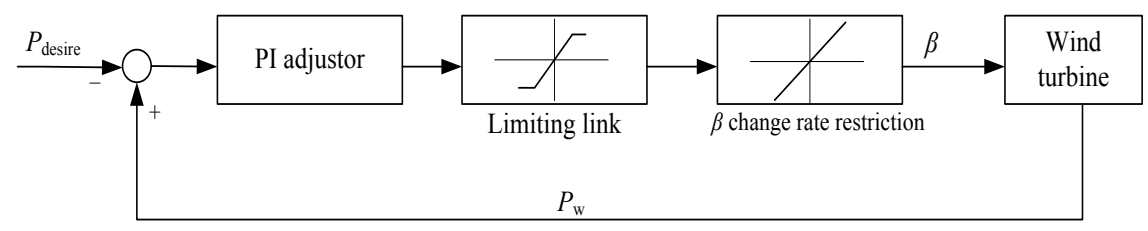

Figure 2. Pitch control model.

fan power and $P_{\text {desire }}$ is the desired output power. Under the action of PI adjustor, limiting link and change rate restriction, $P_{\mathrm{w}}$ is changed with $P_{\text {desire }}$ [9].

The principle of pitch control is to increase pitch angle so that the active output of wind turbine is lower than its rating, and the excess energy is used as the stand-by power of the wind power unit [8]. As shown in Figure 1, the working condition of the unit is changed from point $\mathrm{B}$ to point $\mathrm{A}$, and the pitch angle is reduced from $\beta_{1}$ to $\beta_{3}$, and the maximum active power output of wind turbine is significantly increased. When the frequency of the system is reduced, the pitch angle can be reduced to increase the active output of wind power units and support the frequency response of the system. I Erlich et al. uses pitch control to provide a stand-by capacity of frequency regulation and active participation in system frequency regulation [9]. Theoretically, the pitch control is applicable to full wind speed. However, due to the participation of mechanical parts, the pitch control rate is generally $10 \mathrm{deg} / \mathrm{s}$. In addition, frequent operation of the variable oar system of the wind power unit shortens the service life of the fan and increases the maintenance cost of the fan. Lixin Fan, HaoGuo, et al. [10] proposed a method to control wind power fluctuations with the coordination control of energy storage and pitch angle. Combining the power regulation of the pitch angle and the suppression of energy storage power, it realizes the wind power's good suppression. In F Wilches-Bernal et al. [11] proposed an online pitch control method, which can control the pitch angle according to the real-time load reduction command of the system, and is adaptable to the complex working conditions of the fan operation.

Compared with kinetic energy control, the range of pitch control is large, which can reduce the steady frequency deviation. It is generally used in high wind speed. However, under the influence of mechanical characteristics, the response speed of pitch control is slow. In addition, pitch control is greatly influenced by wind speed fluctuation and can reduce the life of wind turbine.

\subsubsection{Rotor Speed Control}

Rotor speed control can be achieved by increasing or decreasing the rotational speed of wind turbines. But by reducing the rotational speed to increase the power output of the unit, it is easy to cause small disturbance stability. Therefore, the rotor speed control generally adopts the method of over-speed control. As shown in Figure 1, by increasing rotor speed faster than the maximum power tracking point, the wind turbine will enter the over-speed control area. The active output of units is reduced, and a part of reserve capacity is reserved. When 
system frequency decreases, the wind power unit decelerates, which increases the output power of the wind power unit to suppress the frequency change of the system [12].

Under rated wind speed, Ding Lei, Shanyao Yin, et al. [13] used over-speed method to reduce the load of wind turbine, and then add the additional frequency control link to the active power control system of rotor side transmission. Pingyang Jiao, Fang Liu, et al. [14] used the over-speed load-shedding control to regulate frequency of doubly-fed wind turbine. When the power grid frequency is normal, wind turbine runs in the over-speed load-shedding state. When the frequency deviation exceeds the control dead zone, wind turbine can get the speed adjustment according to the current speed and disturbance. Ying Jiang, Xiaoyan Bian et al. [15] took the two factors into consideration that the fan can transmit active power to the micro grid and provide the standby capacity to participate in the system frequency regulation and presents a method of variable load shedding ratio over-speed control. Through the simulation analysis of the micro grid system with doubly fed induction wind turbine generator, it is verified that this method can effectively improve the dynamic characteristics of micro-grid frequency and reduces the cost of active control of wind turbines and can facilitates the stable operation of the micro grid.

Generally speaking, over-speed control has the following characteristics:

1) It has fast response speed and can regulate frequency for a long time.

2) When wind speed is high, the rotor speed of generators is close to the upper limit of the speed. Therefore, it is not suitable to use over-speed control method to adjust the frequency under high wind speed.

3) Over-speed control is generally used to reduce the load, which reduces the operating efficiency. And when the wind speed is very low, the maximum tracking power output by the wind power unit is also low, and the reserved active power reserve capacity will be small.

Compared with pitch control, the response of over-speed control is fast, but it is subject to the rotor speed amplitude, which is generally applicable to the low and medium wind speed. At this time, the power of wind turbines is lower than the rated power, and long-term operation will greatly reduce the benefits of wind farm.

\subsection{Kinetic Energy Control}

When the wind turbine is running normally, the rotor stores a lot of kinetic energy. The rotor can release kinetic energy rapidly to improve the output of active power when the power system has a sudden loss of active power and the frequency decreases [16]. This method can effectively deal with the transient disturbance. Kinetic energy control mainly includes the inertia control and droop control, its principle is in wind turbine control system equipped with a frequency control links, to achieve mutual conversion of kinetic energy and electromagnetic power rotor. 


\subsubsection{Inertial Control}

Inertial control is also known as virtual inertia control or differential inertial control. The principle is to attach a frequency control link to provide an additional active reference signal for the active power control system of the wind turbine, and then make wind turbine can timely response system to adjust its active output frequency. This allows the rotor to respond quickly to transient changes in system frequency, providing a rotation inertia similar to that of a traditional unit [17]. The structure diagram of inertial control is shown in Figure 3 , where $P_{\mathrm{MPPT}}$ is the original active power reference value, and $\Delta P$ is an additional reference signal obtained through the inertial control process. $K_{f}$ is the proportional coefficient and the formula is as follows:

$$
\Delta P=-K_{f} \frac{d f}{d t}
$$

In view of the problem of how to make the doubly-fed wind turbine generator equipped with frequency response capability. Donglin Liu and Qian Wang derived the detailed mathematical model of doubly-fed wind generator set with different vector control technology, at the same time it also analyzed the influence of doubly-fed wind power generator connected to grid in different ways on the inertia of system [18]. In order to overcome the shortcomings of traditional differential inertial control method which can not satisfy the high power shortage disturbance and the safety and stable operation demand of power system with high wind power permeability, Shichun Li, Changhong Deng et al. proposes the method of mode conversion inertial control, which can be used as an alternative technology under the condition of high power shortage and high wind power penetrating power grid [19]. This method can effectively reduce the system frequency drop amplitude and frequency drop speed, and ensure the frequency security of the system. It can also reduce startup times of low-frequency load reduction, and avoid load shedding and reduce economic loss. Based on flexible DC transmission control strategy, combined with the virtual inertia control of the variable-speed constant-frequency wind turbines (WTGS). Yuan Fu, Yi Wang et al. studied the relationship between the virtual rotational inertia of

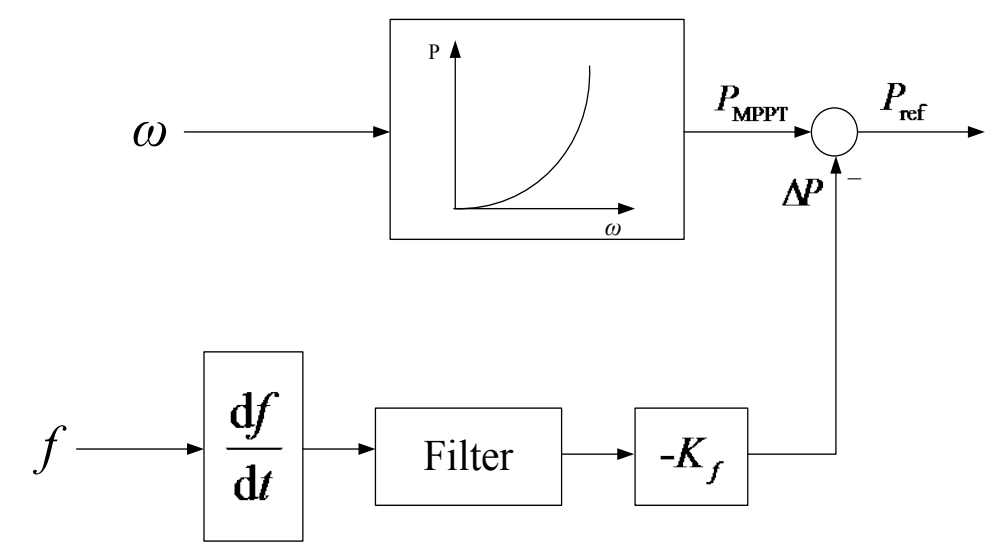

Figure 3. Inertia control block diagram. 
offshore wind power system and the change of power grid frequency, and realized the dynamic support of the offshore wind power system to the power grid frequency, and solved the problem of the lack of inertia of the maritime communication system [20].

When using virtual inertia to adjust frequency, the response speed of conventional generator governor is delayed and the recovery speed of system frequency is reduced. This makes wind turbine need to provide additional power support by continuously lowering the rotor speed, which speeds up the reduction of rotor speed, which is easy to cause the second drop in frequency [21]. To solve this problem, Pingyang Jiao took the drop amplitude of rotor speed in wind turbine during frequency modulation as the input signal, which generated secondary droop control signal by setting and directly superimposes this signal on the active power control signal of the fan [22]. This inhibits the secondary droop of the system frequency and improves the frequency modulation capability of the doubly-fed wind turbine. In general, inertial control is mainly used to prevent the rapid change of frequency in the transient process of power system. The rotor speed will be restored to normal operation state after wind turbines provides temporary active power support when the power grid frequency decreases. The control strategy can not deal with the large power fluctuations, and the duration is short, and the frequency of the second drop is easy to occur [23].

From the above, inertia control can quickly release the rotational kinetic energy stored in wind turbine to the power grid. This makes wind turbines have similar inertia support as conventional units, but there are still some disadvantages:

1) Inertial control can provide short-term inertial support, but it is not adaptive. In addition, the inertial capacity provided by different wind speed states is also different, which makes it difficult to adjust the frequency by changing the rotor speed when the wind speed is very low or high.

2) Inertial control provides additional power support by continuously reducing rotor speed, which is easy to cause the second frequency drop in the process of speed recovery.

\subsubsection{Droop Control}

Droop control block diagram is shown in Figure 4. Droop control is also called slope control or proportional control. The principle is to simulate the same power frequency characteristics as the synchronous generator by adding a droop controller. It adds a reactive power change value proportional to the frequency deviation to the original active power reference value, so as to adjust the active power of the wind turbine in a timely manner [24].

$f_{\text {desire }}$ is the expected frequency and $f_{\mathrm{r}}$ is the actual frequency of the system. The change value of active power $\Delta P$ can be expressed as follows:

$$
\Delta P=-\frac{1}{R} \Delta f
$$

where $R$ is a preset constant. 


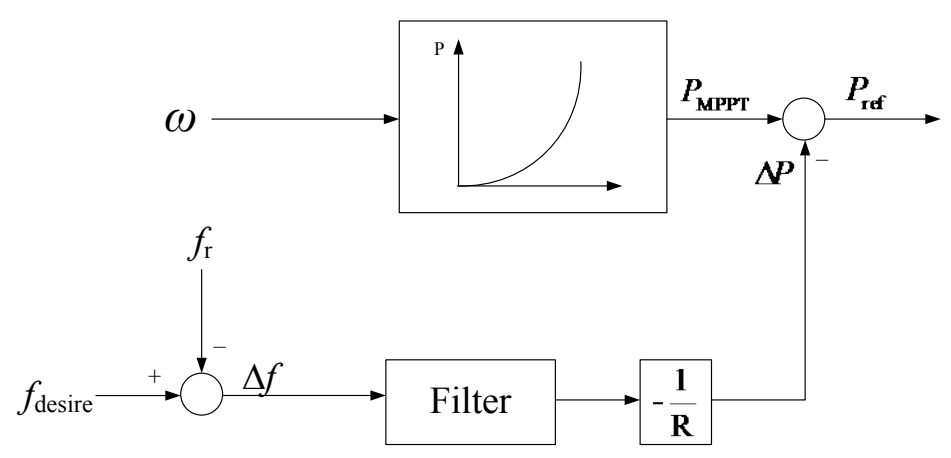

Figure 4. Droop control block diagram.

The frequency control of wind farm connected to the power grid is different from that of traditional generator units. The power output of wind farm is affected by wind speed with randomness and volatility, which causes the droop control strategy using fixed parameter $\mathrm{R}$ to fail to give full play to fan's frequency modulation capability. To deal with this problem, according to the wind turbine output model, using cumulant method and Gram-Charlier series expansion to simplify the algorithm, Wang Jiang and Jiping Lu proposed the equivalent droop control coefficient probabilistic model for the frequency control of wind farm [25]. Wenxia Panet.al adopt the control method of variable droop coefficient according to the operating conditions of wind turbine units, and adopt different methods to adjust the droop control parameters in different ways according to the low, medium and high wind speed zones [26]. In recent years, large-scale development of offshore wind power has made VSC-HVDC transmission technology more and more widely concerned and applied. On the basis of the traditional control strategy of the flexible DC transmission, the constant DC voltage control of the power grid side inverter is reserved to ensure the power balance of the system [27]. Instead of the original constant power control, the rectifier of the wind field side is controlled by AC voltage droop, which can introduce the advantages of droop control without the need of communication and rational dynamic allocation. Considering that inertial control is mainly used to prevent the rapid change of frequency in transient process, droop control is mainly used to reduce the frequency deviation in the steady state process. In practice, the two are often combined to achieve better control effect. In order to ensure that the system frequency can reach the new steady state and continuously compensate the wind turbine generator for the extra active power, Guanfeng Zhang, Junyou Yang, et al. implemented the two control methods in the organic combination of active compensation link and further enhanced the transient and steady-state regulation capability of the doubly fed wind turbine in response to the frequency change in the case of high power and limited power output [28].

Comparing the characteristics of inertia control and droop control in wind turbine, inertia control can eliminate the frequency change more quickly, but droop control has smaller steady-state error value [29]. Droop control can make wind turbine has the same frequency droop characteristics as synchronous 
generator, which is beneficial to the stability of the system frequency. This control process simulates the deviating regulation process of synchronous generator, which is a steady-state process, and system frequency will reach a new stable point.

\section{Study on Improving the Frequency Regulation Capability of Generator Units}

In the current power system, the thermal power unit has the largest share of power generation. Therefore, in the face of power fluctuation and load frequency disturbance, the frequency regulation capability of the thermal power unit plays an important role in the stability of the system. With the large-scale grid connection of wind power, the randomness of wind power generation can bring serious challenges to the safety and reliability of power system, and the frequency regulation capability of the thermal power unit needs to be improved. In order to study the frequency control of power system with high wind permeability more clearly, it is necessary to establish a power system active frequency response model which includes wind power. Power system frequency response model considering wind power is shown in Figure 5, and the parameters are shown in Table 1.

\subsection{Improve Frequency Regulation Capability of AGC Units.}

In the power system, AGC is a system that adjusts the power output of generator sets in a region to respond to the change of load. The existing researches mainly focus on the AGC scheduling margin and allocation strategy of wind farm layer, or focus on improving the secondary frequency regulation capability of AGC units to dynamically balance the fluctuations of wind power. According to the property of AGC, which is mainly responsible for the balance of the minute-level

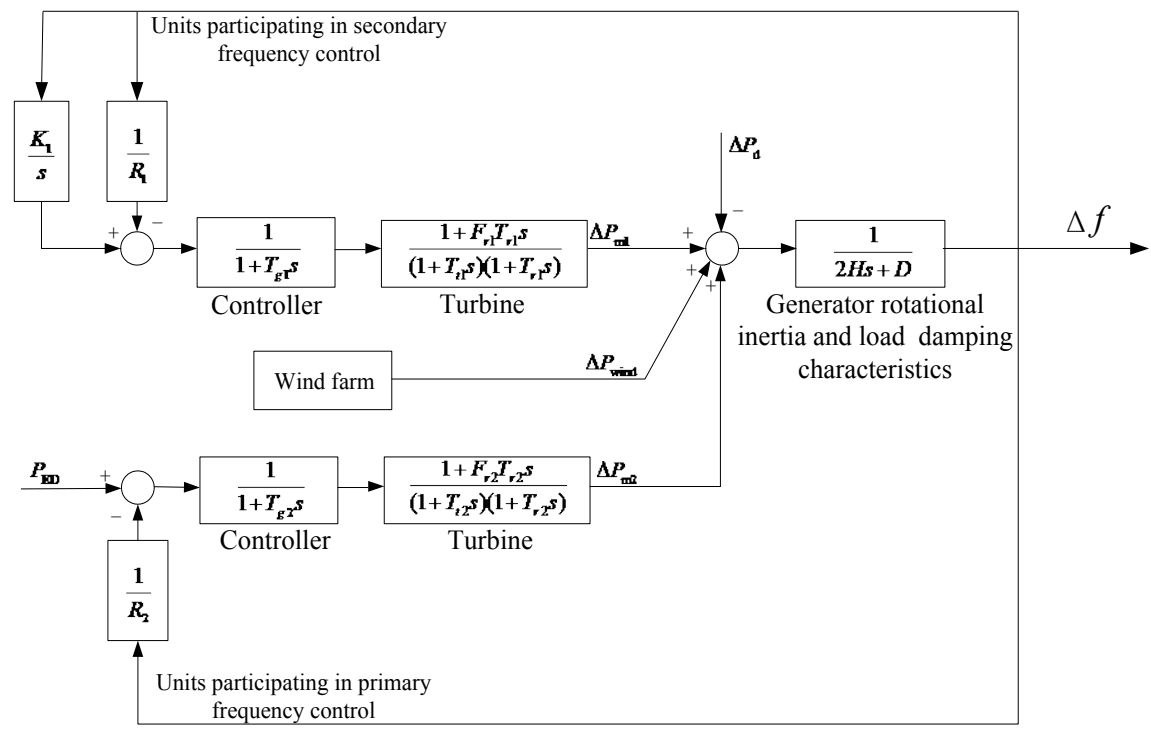

Figure 5. Power system frequency response model considering wind power. 
Table 1. Parameters in the frequency response model.

\begin{tabular}{ccc}
\hline Symbol & Meaning & Unit \\
\hline$\Delta P_{\mathrm{mi}}$ & Conventional turbine mechanical power deviation & p.u. \\
$\Delta P_{\text {wind }}$ & Wind turbine mechanical power deviation & p.u. \\
$\Delta P_{\mathrm{d}}$ & Disturbance power & p.u. \\
$\Delta f$ & Deviation of system frequency & p.u. \\
$P_{\mathrm{ED}}$ & Instruction power & $\mathrm{w}$ \\
$T_{\mathrm{gi}}$ & Speed governor time constant & $\mathrm{sec}$ \\
$F_{\mathrm{ri}}$ & Reheat time constant & $\mathrm{sec}$ \\
$T_{\mathrm{ri}}$ & Turbine time constant & $\mathrm{sec}$ \\
$D$ & Load-damping constant & - \\
$K_{1}$ & Integral gain of secondary frequency control & - \\
$R_{1}$ & Regulation coefficient of primary control & - \\
$H$ & Inertia of generators and motors & - \\
$S$ & Laplace operator & - \\
\hline
\end{tabular}

fluctuation. Songyan Wang and Jilai Yu proposed a coordinated operation control strategy for conventional generators and AGC units in peak load periods [30]. M H Variani and K Tomsovic analyzed the AGC regulation capacity and the regulation rate of the system within the standard deviation range of different wind power fluctuations [31]. Chengming He constructed the real-time control model of the minute-level wind farm and AGC units, and minimized the influence of wind power fluctuations on the adjustment margin under maximum wind power consumption [32]. Lei Zhang, Yi Luo et al. put forward the concept of wide-area coordination factor, and uses the whole network AGC units to realize cross-regional coordination to suppress wind power fluctuation [33]. Chang Xu, Yuan Wei, et al. proposed a new AGC control strategy for wind turbine layer, and adopted different adjustment methods by comparing the dispatching command with the maximum output force of unit [34].

It is proved by practice that the wind power frequency regulation aided by AGC can effectively control the frequency of the unit and improve the ability of the unit to cope with the fluctuation of power and load frequency, thus reducing the operating cost of wind farm.

\subsection{Improve Frequency Regulation Capability of Conventional Units}

However, there are a large number of non-AGC units in the actual system. Base load regulated (BLR) AGC units and base load off-regulated (BLO) AGC units are relatively few, and the secondary frequency regulation capacity of system to increase is limited. Moreover, frequent frequency regulation of AGC units not only causes unit wear, but also sometimes causes partial parameter overshoot of the boiler, reducing efficiency, increasing wear, and increasing operating and 
maintenance costs [35] [36].

When the wind power is connected in a large scale, the increase of conventional units frequency regulation capability is also beneficial to the system to cope with the random fluctuation of wind power. Tao Guo, Rui Qin, et al. utilized the regenerative pumping system to reduce wind power fluctuations and improve the capacity of peak load and frequency regulation [37]. Feng Li et al. designed a sliding module controller to replace the traditional PID controller, so that the whole system can be asymptotically stable in a short time, which effectively inhibited the fluctuation of system frequency and power of inter-system communication line, and improved the frequency regulation capability of units in the multi-area interconnected power network [38]. In addition, when a large amount of wind power capacity is connected to the grid, primary frequency regulation of conventional units takes on a large part of the power disturbance. Aiming at this problem, Qi Wang, Yufeng Guo, et al. put forward the concept of dynamic frequency regulation, which improved the response ability of thermal power units to the low-frequency disturbance under the premise that the unit adjustment coefficient is fixed [39].

Because in the face of wind power fluctuations, conventional units bear the most fluctuations. Compared with improving the frequency regulation capability of AGC units, improving the frequency regulation capability of conventional units has more practical research and application value.

\section{Study on Energy Storage System in Frequency Regulation of the Power System with High Wind Permeability}

As can be seen from previous paper, wind turbines have a certain frequency regulation capability through their own participation in frequency regulation. However, it is difficult to meet the demand of system frequency regulation by the factors such as rotor speed constraint and slow response of pitch control. The energy storage system has the technical characteristics of fast response, flexible control, stable operation and unrestrained operation state of wind power units [40]. Therefore, it can meet the demand of the inertial response of the wind farm and the frequency regulation of the wind farm, which allocates appropriate energy storage in wind farm to participate frequency regulation. This paper establishes the frequency response model of high wind permeability power system under the participation of energy storage system, as shown in Figure 6.

The energy storage technology currently studied can be divided into power side energy storage and load side energy storage by operation character. Power side energy storage refers to the energy storage element combining with distributed power such as wind power, which stabilizes wind power fluctuations and smooths the power curve of distributed power supply, in order to improve the access capacity of distributed power supply [41]. Battery energy storage, flywheel energy storage, superconducting energy storage and so on belong to power side energy storage, which can be in charge and discharge state, have the advantages 


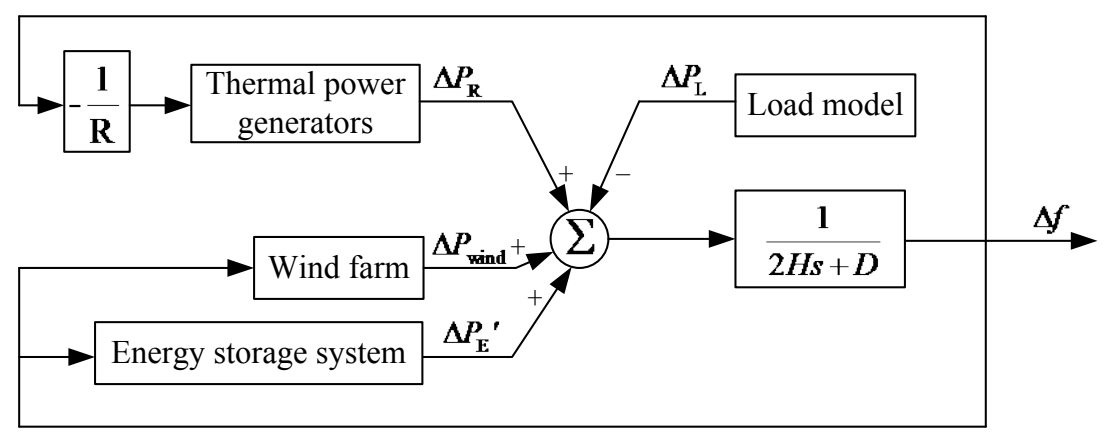

Figure 6. Frequency response model under participation of energy storage system.

of quick response and flexible control. But the disadvantage is that the cost is high and the storage capacity is limited. Load side storage can be controlled by some special load. When the system frequency falls, the system frequency is restored to the expected value by reducing the active power of this type of special load. As control strategy changes the load curve of the system during the frequency adjustment process, it is called load side energy storage.

In the above energy storage forms, flywheels, supercapacitors, superconductors, batteries and fuel cells are gradually applied to wind power frequency modulation, and their basic characteristics are shown in Table 2. With the rapid development of electric and electronic equipment, large capacity converters are constantly emerging. With energy technology becoming increasingly mature, it is easy to realize the energy storage system to assist the wind power system to participate in the system frequency modulation.

In order to prove the effectiveness of the energy storage system in frequency regulation, Shilin Liu et al. proposed the power-frequency control of power system assisted by flywheel [42]. And the simulation results show that compared with the traditional frequency modulation, the energy storage system has high efficiency in participating in frequency regulation. Shucan Zhou and Junxi Tang proposed the coordinated control strategy of wind power and energy storage participating system frequency regulation, which improved the limitation of the wind power unit's self-tuning ability and the frequency of the second drop of the system frequency [43]. Atsushi Tokida et al. proposed a new type of control system based on adjustable-speed pumped-storage generator (ASG) to control the dead zone of wind power frequency control [44]. Zechun Hu and Rui Xia set up the target function which contains the income of the net electric quantity and participation in the frequency regulation and life loss of energy storage [45]. Based on the constraint conditions of power, electric quantity and frequency regulation performance, the optimization model of combined operation of wind turbines and storage system can be solved, which can improve the profit of wind storage power station and give full play to the function of energy storage. In addition, some researches adopt the control strategy combining the energy storage device and wind turbines' own frequency regulation method to reduce the capacity configuration of the energy storage system. Gangui Yan et al. used the 
Table 2. Energy storage system applied to wind power frequency regulation.

\begin{tabular}{|c|c|c|}
\hline Energy storage forms & $\begin{array}{l}\text { Main advantages and } \\
\text { disadvantages }\end{array}$ & Current research stage \\
\hline Flywheel energy storage & $\begin{array}{l}\text { Long life and high efficiency; Low } \\
\text { energy density and high noise }\end{array}$ & $\begin{array}{c}20 \text { MW demonstration project in } \\
\text { New York, USA }\end{array}$ \\
\hline $\begin{array}{l}\text { Superconducting energy } \\
\text { storage }\end{array}$ & $\begin{array}{l}\text { High efficiency and quick response; } \\
\text { Low energy density and high cost }\end{array}$ & $\begin{array}{c}\text { MW demonstration project in } \\
\text { Wisconsin, USA }\end{array}$ \\
\hline Super capacitor & $\begin{array}{l}\text { Quick response and high efficiency; } \\
\text { Low energy density and high cost }\end{array}$ & $\begin{array}{l}\text { MW demonstration project in } \\
\text { German }\end{array}$ \\
\hline Battery storage & $\begin{array}{l}\text { Generally high power and high } \\
\text { efficiency; High cost }\end{array}$ & $\begin{array}{l}\text { China, the United States, Japan } \\
\text { and other countries have MW } \\
\text { demonstration projects }\end{array}$ \\
\hline Fuel cell & $\begin{array}{l}\text { High energy and long time; Low } \\
\text { efficiency }\end{array}$ & $\begin{array}{l}\text { Study by k. v. idyanandan } \\
\text { laboratory in India }\end{array}$ \\
\hline
\end{tabular}

energy storage to compensate system inertia, so that wind storage combined system as a whole provides active power to participate in the grid frequency regulation [46]. Fufeng Miao et al. kept the rotational inertia constant, so that the inertia time constant of rotor speed changes with different wind speed [47]. When the frequency changes, the wind power unit firstly responds to the inertia demand of wind farm, and then uses the energy storage system to make up for the shortage of the wind turbine's own inertia.

It is necessary to add additional equipment for the energy storage system to assist wind power frequency modulation, which is bound to conflict with the economy of wind field operation. In order to reduce the cost of wind farm operation, an energy storage system of appropriate size should be configured on the basis of economic evaluation. Liyan Qu and Qiao Wei quantitatively analyzed the impact of large-scale wind power grid connection on power grid frequency, providing a basis for the economic evaluation of energy storage participation in system frequency modulation [48]. Ruili Ye analyzed the prediction error of wind power, and optimized the capacity of energy storage device of wind power plant by using cost and benefit analysis [49].

In general, the energy storage system can effectively suppress the power fluctuations, but also make up for the defects of the wind turbines' own frequency regulation method, and obtain more efficient and effective active control. In addition, if the energy storage unit is added to the wind turbine, a better frequency regulation effect can be obtained, and the capacity configuration that depends only on energy storage frequency regulation is reduced.

\section{Conclusion}

In order to alleviate the global energy crisis and reduce environmental pollution, wind power has developed rapidly. At the same time, a large amount of wind power is connected to the power system, which reduces the system inertia, and the intermittent and uncontrollable wind farms pose a great challenge to the 
frequency stability of the power system. Firstly, this paper analyzes several control strategies of wind power unit's own participation in frequency regulation, and analyzes the advantages and disadvantages of various control strategies. Then, this paper describes the research of improving the frequency regulation capability of generator sets. At present, such research is based on theory and simulation, and is not applied to actual power system. It is necessary to carry out simulation and experiment on the operation scenario of power system more in accordance with the complex operating conditions of wind power operation. Finally, the research of energy storage system in power system frequency regulation is also introduced in this paper. With the decrease of the cost of energy storage technology, the research of large-scale energy storage system participating in system frequency regulation will become more and more practical.

\section{Conflicts of Interest}

The authors declare no conflicts of interest regarding the publication of this paper.

\section{References}

[1] China Electricity Council (CEC) (2018) 2017-2018 National Power Supply and Demand Situation Analysis and Forecast Report. http://www.cec.org.cn/guihuayutongji/gongzuodongtai/2018-02-01/177584.html

[2] Chen, M.X. (2017) New Energy Development Leads European Power Changes. China Power Enterprise Management, No. 34, 94-97.

[3] Global Wind Energy Council (GWEC) (2017) Global Wind Power Loading Statistics in 2016. Wind Energy, No. 2, 52-57.

[4] Xue, Y.S., Lei, X., et al. (2014) A Review on Impacts of Wind Power Uncertainties on Power Systems. Proceedings of the CSEE, 34, 5029-5040.

[5] Muljadi, E., Gevorgian, V., Singh, M. and Santoso, S. (2012) Understanding Inertial and Frequency Response of Wind Power Plants. IEEE Power Electronics and Machines in Wind Applications, Denver, 16-18 July 2012, 1-8.

[6] Singarao, V.Y. and Rao, V.S. (2016) Frequency Responsive Services by Wind Generation Resources in United States. Renewable \& Sustainable Energy Reviews, 55, 1097-1108. https://doi.org/10.1016/j.rser.2015.11.011

[7] Zhang, Z.S., Sun, Y.Z., Lin, J., et al. (2012) Coordinated Frequency Regulation by Doubly Fed Induction Generator-Based Wind Power Plants. IET Renewable Power Generation, 6, 38-47. https://doi.org/10.1049/iet-rpg.2010.0208

[8] Moutis, P., Loukarakis, E., Papathanasiou, S., et al. (2009) Primary Load-Frequency Control from Pitch-Controlled Wind Turbines. IEEE Bucharest PowerTech, Bucharest, 28 June-2 July 2009, 1-7.

[9] Erlich, I. and Wilch, M. (2010) Primary Frequency Control by Wind Turbines. IEEE Power \& Energy Society General Meeting, Providence, RI, 25-29 July 2010, 1-8.

[10] Fan, L.X., Guo, H., et al. (2016) Wind Power Fluctuation Suppression Based on Control Coordination between Energy Storage and Pitch Angle. Electric Power Automation Equipment, No. 9, 100-105.

[11] Wilches-Bernal, F., Chow, J.H. and Sanchez-Gasca, J.J. (2015) Doubly Fed Induction Generator (DFIG)-Based Wind Farm Control Framework for Primary Frequency and Inertial Response Application. IEEE Transactions on Power Systems, 1, 
1723-1727.

[12] Bao, Y.Q., Li, Y., Wang, C.N., et al. (2015) On Demand Response Participating in the Frequency Control of the Grid under High Wind Penetration. Power System Protection and Control, 43, 32-37.

[13] Lei, D., Yin, S.Y., et al. (2015) Integrated Frequency Control Strategy of DFIGs Based on Virtual Inertia and Over-Speed Control. Power System Technology, No. 9, 2385-2391.

[14] Jiao, P.Y., Liu, F., et al. (2016) Frequency Regulation Strategy of DFIG in Micro-Grid System Based on Subsection Control. Electrical Measurement \& Instrumentation, No. 12, 69-74.

[15] Jiang, Y., Bian, X.Y., et al. (2017) Research on Doubly Fed Induction Generator Participation in Microgrid Frequency regulation Based on Variable Load Shedding Ratio Over-Speed Control. Electric Machines \& Control Application, No. 9, 118-124.

[16] Peng, X. and Liu, R. (2011) Research on the Frequency Regulation of Aiding System of VSCF Double-Fed Wind Generator. Power System Protection and Control, No. 11, 56-61.

[17] Wang, Q., Bai, L., et al. (2014) The Inertial Control of Double-Fed Wind-Driven Generator Set. Electric Switcher, No. 4, 24-28.

[18] Liu, D. and Wang, Q. (2016) Research on Virtual Inertial Controller of DFIG. Electrical Measurement \& Instrumentation, No. 14, 46-50.

[19] Li, S., Deng, C., et al. (2016) An Inertial Control Method of Doubly Fed Induction Generators Suitable for Power Grid with High Wind Power Penetration. Automation of Electric Power Systems, 40, 33-38.

[20] Fu, Y., Wang, Y., et al. (2014) Virtual Inertia Control of Offshore Wind Farms with VSC-HVDC for Grid-Connection. Electrical Measurement \& Instrumentation, No. $1,43-48$

[21] Tarnowski, G.C., Kjar, P.C., Sorensen, P.E., et al. (2009) Variable Speed Wind Turbines Capability for Temporary Over-Production. Power \& Energy Society General Meeting, 26-30 July 2009, 1-7.

[22] Jiao, P. (2015) Research on Frequency Strategy of Doubly-Fed Induction Generator in Microgrid. Harbin Institute of Technology, Harbin.

[23] Jiang, Q. and Gong, Y. (2015) Review of Wind Power Integration Control with Energy Storage Technology. Power System Technology, 39, 3360-3368.

[24] Ramtharan, G., Ekanayake, J.B. and Jenkins, N. (2007) Frequency Support from Doubly Fed Induction Generator Wind Turbines. IET Renewable Power Generation, 1, 3-9.

[25] Jiang, W. and Lu, J. (2014) Research on Probabilistic Model of Droop Control Coefficient of Grid-Connected Wind Farm. Power System Technology, 38, 3431-3435.

[26] Pan, W., Quan, R. and Wang, F. (2015) A Variable Droop Control Strategy for Doubly-Fed Induction Generators. Automation of Electric Power Systems, 39, 126-131.

[27] Tian, Y., Miu, Q., et al. (2016) Droop Control Strategy for Wind Power Decentralized Integration Based on VSC-HVDC Systems. Automation of Electric Power Systems, No. 3, 103-109.

[28] Zhang, G., Yang, J., et al. (2017) Primary Frequency Regulation Strategy of DFIG Based on Virtual Inertia and Frequency Droop Control. Transactions of China Electrotechnical Society, No. 22, 225-232. 
[29] Rezkalla, M., Marinelli, M., Pertl, M., et al. (2016) Trade-Off Analysis of Virtual Inertia and Fast Primary Frequency Control during Frequency Transients in a Converter Dominated Network. IEEE Innovative Smart Grid Technologies, Melbourne, 28 November-1 December 2016, 890-895.

[30] Wang, S. and Yu, J. (2013) Coordinated Dispatch Regulation Strategy between Non-AGC Units and AGC Units with High Wind Power Penetration. Proceedings of the CSEE, 33, 156-163.

[31] Variani, M.H. and Tomsovic, K. (2013) Distributed Automatic Generation Control Using Flatness-Based Approach for High Penetration of Wind Generation. IEEE Transactions on Power Systems, 28, 3002-3009. https://doi.org/10.1109/TPWRS.2013.2257882

[32] He, C., Wang, H., Wei, Z., et al. (2015) Distributed Coordinated Real-Time Control of Wind Farm and AGC Units. Proceedings of the CSEE, 35, 302-309.

[33] Zhang, L., Luo, Y., et al. (2016) Trans-Regional and Distributed Optimal Coordination Control of AGC Units under Large-Scale Wind Power Grid. Transactions of China Electrotechnical Society, No. 9, 42-49.

[34] Xu, C., Wei, Y., et al. (2017) Research on Automatic Generation Turbine Control Strategy of Large Wind Turbine. Power System Protection and Control, No. 2, 69-74.

[35] Banakar, H., Luo, C. and Ooi, B.T. (2008) Impacts of Wind Power Minute-toMinute Variations on Power System Operation. IEEE Transactions on Power Systems, 23, 150-160. https://doi.org/10.1109/TPWRS.2007.913298

[36] Jiang, X., Li, H., Sheng, K., et al. (2011) The Analysis and Application of AGC in Hunan Power Grid. Hunan Electric Power, 31, 98-101.

[37] Guo, T., Qin, R., et al. (2014) Frequency Regulation Method with Using Steam Turbine Regenerators in Wind Power System. Energy Conservation Technology, No. 2, 108-111.

[38] Li, F., Yu, W. and Zhang, Z. (2018) Load Frequency Control for Multi-Area Power System with Wind Power Generation. Water Resources and Power, No. 1, 195-199.

[39] Wang, Q., Guo, Y.F., et al. (2018) Primary Frequency Regulation Strategy of Thermal Units for a Power System with High Penetration Wind Power. Proceedings of the CSEE, No. 4, 974-984

[40] Miao, F., Tang, X. and Qi, Z. (2015) Analysis of Frequency Characteristics of Power System Based on Wind Farm-Energy Storage Combined Frequency Regulation. High Voltage Engineering, 41, 2209-2216.

[41] Feng, Q., Zhou, Y., Gui, J., et al. (2017) Literature Review on Frequency Regulation Technologies of the Power System with Large Scale Wind Power. Electrical Measurement \& Instrumentation, 54, 39-46.

[42] Liu, S., Wen, J. and Sun, H. (2015) Hybrid Energy Storage System and Its Control Strategies Intended for Windpower Conditioning. Proceedings of the CSEE, 35, 95-102.

[43] Zhou, S. and Tang, J. (2017) Research on Coordinated Control Strategy of Wind Power and Energy Storage in System Frequency Regulation. Mechanical \& Electrical Engineering Technology, No. 11, 31-35.

[44] Tokida, A., Tahara, S., Yoshida, Y., et al. (2016) Frequency Control with Dead Band by Adjustable-Speed Pumped-Storage Generator for Power System with Wind Farms. 19th International Conference on Electrical Machines and Systems, Chiba, 13-16 November 2016, 1-6. 
[45] Hu, Z., Xia, R., et al. (2016) Joint Operation Optimization of Wind-Storage Union with Energy Storage Participating Frequency Regulation. Power System Technology, 40, 2251-2256.

[46] Yan, G., Wang, Y., Zhong, C., et al. (2016) Frequency Control Strategy for Wind Storage Combined System. Electric Power Construction, 37, 55-60.

[47] Miao, F., Tang, X. and Qi, Z. (2015) Capacity Configuration Method for Wind Power Plant Inertia Response Considering Energy Storage. Automation of Electric Power Systems, 39, 6-11.

[48] Qu, L. and Wei, Q. (2011) Constant Power Control of DFIG Wind Turbines with Supercapacitor Energy Storage. IEEE Transactions on Industry Applications, 47, 359-367. https://doi.org/10.1109/TIA.2010.2090932

[49] Ye, R., Guo, Z., Liu, R., et al. (2014) A Windenergy Storage Capacity Optimization Method Based on the Analysis of Wind Power Prediction Error. Automation of Electric Power Systems, 38, 28-34. 